JOURNAL OF

SYNCHROTRON

RADIATION

ISSN 1600-5775

\title{
A compact furnace for in situ X-ray absorption spectroscopy: design, fabrication and study of cationic oxidation states in $\operatorname{Pr}_{6} \mathrm{O}_{11}$ and $\mathrm{NiO}$
}

\author{
Suchinda Sattayaporn, ${ }^{\mathrm{a} *}$ Somboonsup Rodporn, ${ }^{\mathrm{a}}$ Pinit Kidkhunthod, ${ }^{\mathrm{a}}$ \\ Narong Chanlek, ${ }^{a}$ Chutarat Yonchai ${ }^{\mathrm{a}}$ and Saroj Rujirawat ${ }^{\mathrm{b}, \mathrm{c}}$
}

Received 8 October 2020

Accepted 30 November 2020

Edited by K. Kvashnina, ESRF - The European Synchrotron, France

Keywords: X-ray absorption spectroscopy; in situ cells; transmittance and fluorescence; instrumentations; in situ XAFS.

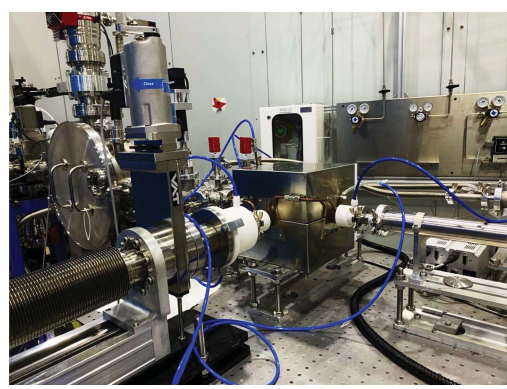

C 2021 International Union of Crystallography

\footnotetext{
aSynchrotron Light Research Institute, Nakhon Ratchasima 30000, Thailand, 'b School of Physics, Institute of Science, Suranaree University of Technology, Nakhon Ratchasima 30000, Thailand, and ${ }^{{ }}$Research Network NANOTEC-SUT on Advanced Nanomaterials and Characterization, School of Physics, Institute of Science, Suranaree University of Technology, Nakhon Ratchasima 30000, Thailand. *Correspondence e-mail: suchinda@slri.or.th
}

A well designed compact furnace has been designed for in situ X-ray absorption spectroscopy (XAS). It enables various heat ramps from $300 \mathrm{~K}$ to $1473 \mathrm{~K}$. The furnace consists of heaters, a quartz tube, a circulated refrigerator and a power controller. It can generate ohmic heating via an induction process with tantalum filaments. The maximum heating rate exceeds $20 \mathrm{~K} \mathrm{~min}^{-1}$. A quartz tube with gas feedthroughs allows the mixing of gases and adjustment of the flow rate. The use of this compact furnace allows in situ XAS investigations to be carried out in transmission or fluorescence modes under controlled temperature and atmosphere. Moreover, the furnace is compact, light and well compatible to XAS. The furnace was used to study cationic oxidation states in $\operatorname{Pr}_{6} \mathrm{O}_{11}$ and $\mathrm{NiO}$ compounds under elevated temperature and reduced atmosphere using the in situ X-ray absorption near-edge structure (XANES) technique at beamline 5.2 SUT-NANOTEC-SLRI of the Synchrotron Light Research Institute, Thailand. At room temperature, $\operatorname{Pr}_{6} \mathrm{O}_{11}$ contains a mixture of $\operatorname{Pr}^{3+}$ and $\operatorname{Pr}^{4+}$ cations, resulting in an average oxidation state of +3.67 . In situ XANES spectra of $\operatorname{Pr}\left(L_{3}\right.$-edge $)$ show that the oxidation state of $\operatorname{Pr}^{4+}$ cations was totally reduced to +3.00 at $1273 \mathrm{~K}$ under $\mathrm{H}_{2}$ atmosphere. Considering $\mathrm{NiO}, \mathrm{Ni}^{2+}$ species were present under ambient conditions. At $573 \mathrm{~K}$, the reduction process of $\mathrm{Ni}^{2+}$ occurred. The $\mathrm{Ni}^{0} / \mathrm{Ni}^{2+}$ ratio increased linearly with respect to the heating temperature. Finally, the reduction process of $\mathrm{Ni}^{2+}$ was completely finished at $770 \mathrm{~K}$.

\section{Introduction}

X-ray absorption spectroscopy (XAS) performed at synchrotron sources has been considered a powerful characterization tool for several decades due to its high sensitivity and its capability to probe almost all elements of the periodic table. This technique is non-destructive and is suitable for studying a large variety of materials such as powders, solids, liquids, glasses, thin films, crystals and amorphous compounds. Basically, XAS spectra consist of X-ray absorption near-edge structure (XANES) and extended X-ray absorption fine structure (EXAFS). The XAS spectra can be used to determine the cationic/anionic oxidation state, chemical geometry, coordination number, oxygen vacancy and local structure of a probed element. Therefore, it is frequently used to sustainably develop physical, thermo-electric, catalytic or magnetic properties of advanced and novel materials (Yao et al., 2019; Song et al., 2019; Jaiban et al., 2018; Sumrunronnasak et al., 2018; Sriplai et al., 2018; Boonruang et al., 2018). It is well known that the performance of the XAS technique can be 
enhanced by utilizing in situ cells which enable experimental conditions, such as elevated temperature, vacuum, inert and reducing/oxidizing atmosphere, to be controlled in real time. According to the literature, in situ heating cells have been developed using different approaches for time- or temperature-resolved XAS techniques (Tamura et al., 1995; Lamberti et al., 2003; Huwe \& Fröba, 2004; Meneses et al., 2006; An et al., 2014; Yamamoto et al., 2018; Zhao et al., 2017; Inukai et al., 2015). Most were initially fabricated for the purpose of XAS investigations on catalyst materials (van Bokhoven et al., 1999; van der Eerden et al., 2000; Grunwaldt et al., 2001; Kappen et al., 2001; Bolin et al., 2013; Yamamoto et al., 2018; Mathisen et al., 2018). Recently, the in situ XAS technique has also been applied to characterize other advanced and novel materials (Steiner et al., 2019; Deb et al., 2006; Hashimoto et al., 2007; Massa et al., 2015; Marini et al., 2018; Mastelaro et al., 2018; Chin et al., 2019). Nevertheless, these in situ heating cells possess some limitations in terms of maximum temperature, heating rate, flowing gas or measurement mode. Therefore, it has been interesting to design an in situ XAS furnace with optimized functionalities and qualities.

In this work, we demonstrate the design, thermal simulation, fabrication and performance tests for an in situ XAS furnace. The compact furnace was designed simply using inexpensive materials. The sample holder is designed to be adaptable for in situ transmission and fluorescence XAS measurements. The furnace can be easily installed at XAS synchrotron facilities and combined with gas lines. To the best of our knowledge, the compact in situ furnace possesses superior specifications to the previously mentioned in situ heating cells in terms of maximum temperature, heating rate and capability to perform XAS measurements in both transmission and fluorescence modes. In addition, the furnace atmosphere can be controlled by pumping under vacuum or flowing any type of gas such as $\mathrm{H}_{2}, \mathrm{~N}_{2}, \mathrm{O}_{2}, \mathrm{Ar}$, $\mathrm{He}$ or $\mathrm{CO}_{2}$ with an adjustable rate between 1 and $100 \mathrm{ml} \mathrm{min}^{-1}$. Finally, we tested the quality and performance of the fabricated compact furnace at beamline 5.2 SUT-NANOTEC-SLRI XAS at the Synchrotron Light Research Institute (SLRI), Nakhon Ratchasima, Thailand, which is capable of tuning X-ray energy from $1.2 \mathrm{keV}$ to $13.0 \mathrm{keV}$. In situ XAS experiments were operated from $300 \mathrm{~K}$ to $1473 \mathrm{~K}$ under $\mathrm{H}_{2}$ atmosphere. The XANES experiments were performed by probing $\mathrm{Pr}$ and $\mathrm{Ni}$ elements at the $L_{3}$-edge and $K$-edge in transmission and fluorescence modes, respectively. The obtained spectra were normalized using Athena software (Ravel \& Newville, 2005). A linear combination fit was also performed to investigate changes in the oxidation states and weight percentages of cationic ions in $\operatorname{Pr}_{6} \mathrm{O}_{11}$ and $\mathrm{NiO}$ compounds.

Based on conventional XAS measurements in the tender $\mathrm{X}$-ray range at beamline 5.2, SLRI, such a probing $\mathrm{Si}, \mathrm{Mg}$ or Al XANES/EXAFS experiment could be performed by using double single-crystals of beryl (1010) as a monochromator and sealing the photon-in and photon-out windows with polypropylene tape. Note that a flowing $\mathrm{He}$ atmosphere is necessary to obtain a good XAS signal.

\section{In situ compact furnace}

The compact furnace was designed and developed to achieve high performances and optimal functionalities for in situ XAS measurement. The furnace system consists of four main components. First, a compact furnace equipped with a thermocouple and a proportional integral derivative (PID) controller. The PID controller has a set of digital temperature programs, including two patterns; the maximum number of steps is 16 . Second, a three-way quartz tube, used as the sample holder. Third, flanged windows, enclosing the quartz tube for the photon-in pathway A and the photon-out pathways B and C. The windows are sealed by Kapton (polyimide) tape of thickness $50 \mu \mathrm{m}$. Kapton can be replaced by another window material such as polypropylene or beryllium, depending on the X-ray energy range. Furthermore, the feedthroughs of the gas inlet and outlet, mounted at the flange windows, allow the distribution of various types of gas such as $\mathrm{H}_{2}, \mathrm{~N}_{2}, \mathrm{He}, \mathrm{Ar}, \mathrm{CO}_{2}$ and $\mathrm{O}_{2}$ into the quartz tube. The flow rate can be adjusted from 1 to $100 \mathrm{ml} \mathrm{min}^{-1}$ with gas mass flow controllers. Fourth, a cooling chamber, connected to a watercirculated refrigerator. It should be noted that flowing He gas is suggested during XAS measurements at photon energies below $3000 \mathrm{eV}$ in fluorescence mode to improve the signal-tonoise ratio; above $3000 \mathrm{eV}$, experiments can be performed under air. Fig. 1 shows the construction drawing of the entire compact furnace; specifications of the compact furnace are summarized in Table 1. The main components of the in situ furnace are depicted and detailed in Fig. 2 and Table 2, respectively.

A thermal simulation was also conducted for the entire area of the furnace using SolidWorks (https://www.solidworks. $\mathrm{com} /$ ) software as shown in Fig. 1 (inset). The heating zone was uniformly distributed and covered all of the furnace's body, precisely in an area of $100 \mathrm{~mm} \times 100 \mathrm{~mm}$. With these specifications, the maximum temperature can exceed $1473 \mathrm{~K}$. The heating rate can be varied between 1 and $20 \mathrm{~K} \mathrm{~min}^{-1}$. The furnace is equipped with a PID controller, enabling 16 heating steps to be programmed. Moreover, a sample holder was specially designed to be adaptable for measuring in situ XAS in transmission and fluorescence modes. Hence, the ceramic holder was cut and mounted at angles of $45^{\circ}$ and $90^{\circ}$. Here, the sample holder can be put inside the three-ways quartz tube and placed together in the middle of the furnace.

Regarding Fig. 1, the monochromatic X-ray beam enters via entrance $\mathrm{A}$ and reaches the sample at the furnace center. In the case of transmission mode, the X-ray beam penetrates the sample and passes through the ionization chamber via pathway B. On the other hand, fluorescence emission can occur and is measured by using a solid-state detector at the end of pathway C. Here, we used a silicon drift detector (SDD), which is extremely sensitive to elevated temperature. Therefore, we fabricated a cooling chamber to prevent heat damage during in situ XAFS measurement. It was inserted between the heating zone and the SDD (see ' 5 ' in Fig. 1). This chamber has a window flange at the end, equipped with a high- 


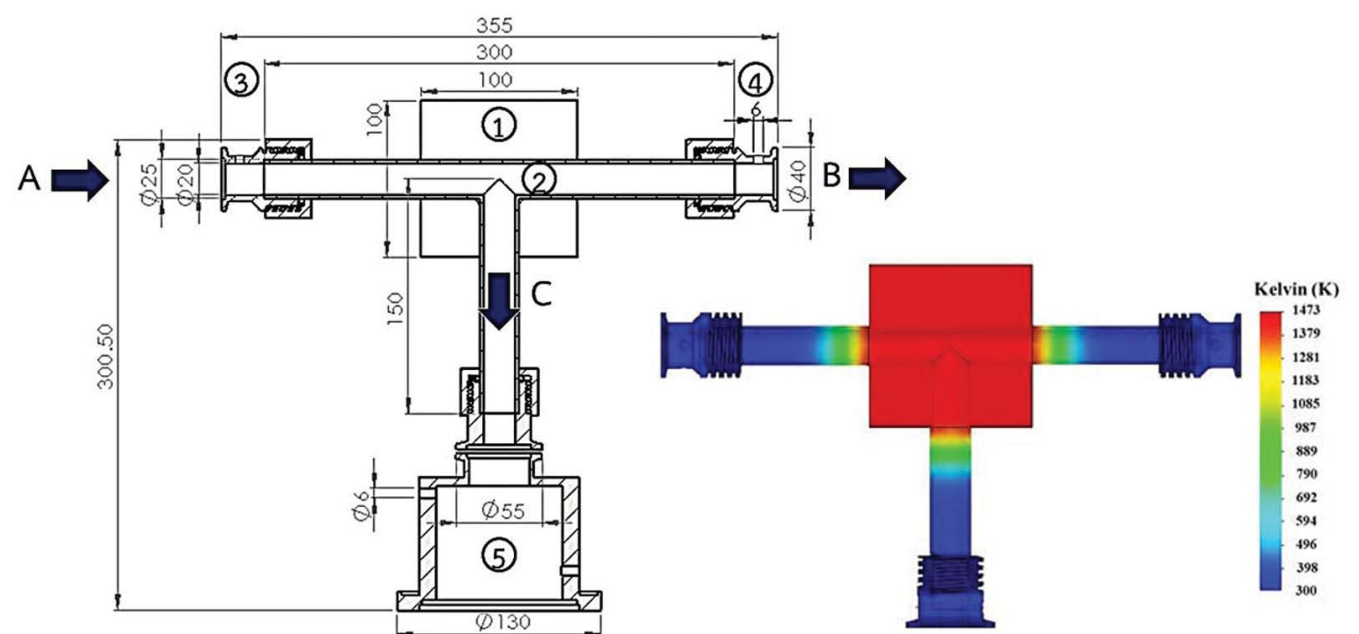

Figure 1

Construction drawing of the compact furnace with labeled lengths in millimetres and thermal simulation of the entire compact furnace in $\mathrm{K}$ (inset).

Table 1

In situ heating cell specifications and parameters.

\begin{tabular}{ll}
\hline Specifications & Details \\
\hline Cell dimensions (length $\times$ width $\times$ height) & $230 \times 230 \times 230 \mathrm{~mm}$ \\
Isolator type & Ceramic fiber broad $(1873 \mathrm{~K})$ \\
Stainless steel thickness & $2.5 \mathrm{~mm}$ \\
Sample-transmission distance & $30 \mathrm{~mm}$ \\
Sample-fluorescence distance & $30 \mathrm{~mm}$ \\
Temperature range & $273-1473 \mathrm{~K}$ \\
Heating rate range & $1-20 \mathrm{~K} \mathrm{~min}{ }^{-1}$ \\
Heater power & $1.3 \mathrm{KW}$ \\
Heater voltage & $220 \mathrm{~V}$ \\
Thermocouple & $\mathrm{Pt} 10 \% \mathrm{Rh} / \mathrm{Pt}(\mathrm{R}-$ type $)$ \\
Constant-temperature area & $100 \times 100 \mathrm{~mm}$ \\
Total number of heating steps & 16 \\
\hline
\end{tabular}

performance refrigerated circulator (JULABO, model Corio CD-200F). The maximum cooling temperature was $178 \mathrm{~K}$.

In order to test its quality and heating performance, all of the main components were systematically connected and installed at beamline 5.2 SUT-NANOTEC-SLRI XAS at
Table 2

Main components of the in situ compact furnace.

\begin{tabular}{|c|c|c|}
\hline Number & Item & Material \\
\hline 1 & Furnace body (bottom) & $\begin{array}{l}\text { Heater, ceramic }\left(\mathrm{Al}_{2} \mathrm{O}_{3}\right) \text {, } \\
\text { stainless steel }\end{array}$ \\
\hline 2 & Furnace body (top) & Stainless steel \\
\hline 3 & Three-way quartz tube & Quartz \\
\hline 4 & Flange $(a)$ & Tapflon \\
\hline 5 & Flange $(b)$ & Tapflon \\
\hline 6 & O-ring & Rubber \\
\hline 7 & Cooling coil & Copper \\
\hline 8 & $\begin{array}{l}\text { Adapter for thermocouple } \\
\text { (KF40) }\end{array}$ & Tapflon \\
\hline 9 & Flange $(c)$ & Tapflon \\
\hline
\end{tabular}

SLRI. Fig. 3 shows a photograph of the in situ XAS system showing its configuration.

The functionalities of the compact furnace were tested by recording the measured temperature inside the furnace under $\mathrm{N}_{2}$ atmosphere at a flow rate of $10 \mathrm{ml} \mathrm{min}^{-1}$. The heating temperature was ramped from room temperature to $1473 \mathrm{~K}$ with different heating rates of $2,5,10$ and $20 \mathrm{~K} \mathrm{~min}^{-1}$. Once the maximum temperature was reached, the furnace was held at $1473 \mathrm{~K}$ for at least $30 \mathrm{~min}$ to observe any thermal fluctuation. For all heating rates, the measured and set temperatures were well superposed, as shown in Fig. 4. Fig. 4 shows that the invented furnace achieved heating from room temperature to a maximum temperature of $1200 \mathrm{~K}$ with no thermal fluctuation during the tests at heating rates of 2, 5, 10 and $20 \mathrm{~K} \mathrm{~min}^{-1}$.

\section{X-ray absorption spectroscopy}

After furnace testing, in situ XAS experiments were carried out in order

Main components of the in situ compact furnace: $(a)$ top view and $(b)$ side view. See Table 2 for description of numbers. 


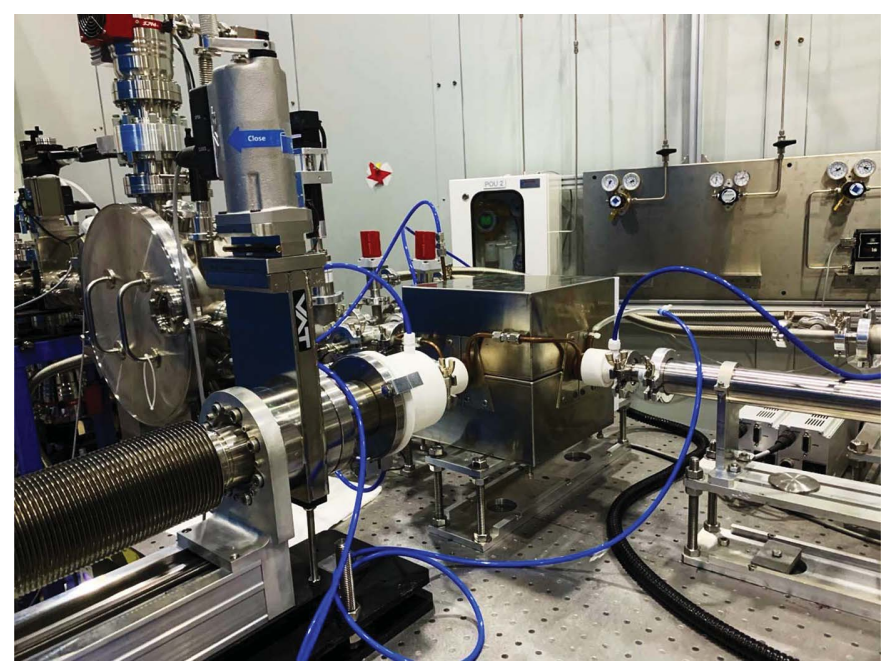

Figure 3

In situ XAS system for transmission and fluorescence in situ XAS measurements.

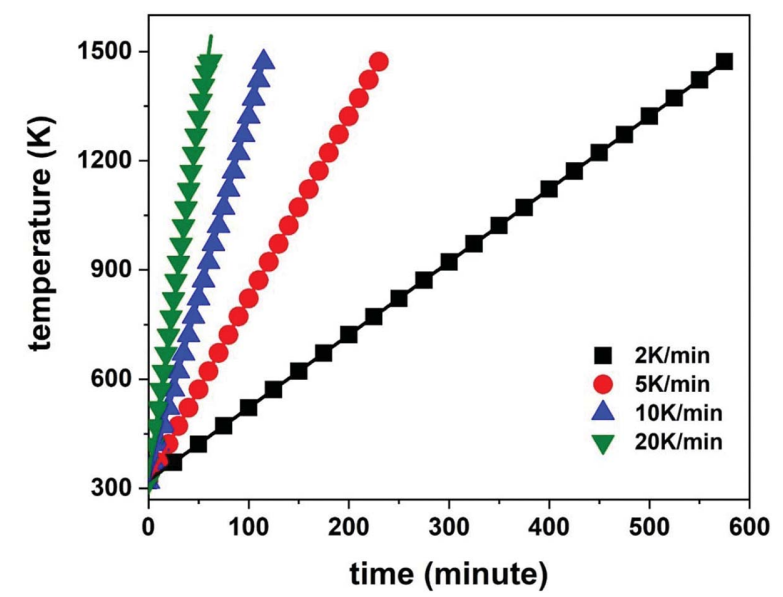

Figure 4

Set (symbol) and measured (line) temperatures as a function of time at heating rates of $2,5,10$ and $20 \mathrm{~K} \mathrm{~min}^{-1}$.

to study the reduction process of cationic ions in $\operatorname{Pr}_{6} \mathrm{O}_{11}$ and $\mathrm{NiO}$ fine powders in transmission and fluorescence modes, respectively. In this section, we determine the effect of temperature on cationic oxidation state in $\operatorname{Pr}_{6} \mathrm{O}_{11}$ and $\mathrm{NiO}$ compounds. Fine powders were ground and compressed into pellets of diameter $15 \mathrm{~mm}$. Our furnace was set up and in situ XAS experiments were performed at beamline 5.2 to record the $\mathrm{Pr}$ and $\mathrm{Ni}$ XANES in transmission and fluorescence modes, respectively. The stored current was around $120 \mathrm{~mA}$. Germanium (220) double single-crystals were utilized as a monochromator to probe the Pr and Ni elements at their $L_{3^{-}}$ edge $(5964 \mathrm{eV})$ and $K$-edge $(8333 \mathrm{eV})$, respectively. The data interval was set as $0.3 \mathrm{eV}$. The measurements were carried out at various temperatures ranging from 300 to $1473 \mathrm{~K}$ under $\mathrm{H}_{2}$ reducing atmosphere. Using Athena software, the recorded XANES spectra were normalized and interpreted to study the changes in the oxidation states for Pr and Ni cations.

\section{1. $\operatorname{Pr} \boldsymbol{L}_{3}$-edge XANES}

$\operatorname{Pr}_{6} \mathrm{O}_{11}$ commercial powder was compressed into a pellet of diameter $15 \mathrm{~mm}$ and placed at an angle of $90^{\circ}$ in the sample holder. Heating steps were programed from room temperature to $1473 \mathrm{~K}$ with a heating rate of $10 \mathrm{~K} \mathrm{~min}^{-1}$. Firstly, XAS measurements were made in transmission mode by probing Pr at its $L_{3}$ absorption edge at $5964 \mathrm{eV}$. The photon energy was tuned using the Ge (220) double-crystal monochromator. In situ XANES spectra were collected during heating the sample under $\mathrm{H}_{2}$ atmosphere with a flow rate of $20 \mathrm{ml} \mathrm{min}^{-1}$. Fig. 5 shows all the normalized spectra at various temperatures.

Consider a mixture of $\operatorname{Pr}^{3+}$ and $\operatorname{Pr}^{4+}$ cations in $\operatorname{Pr}_{6} \mathrm{O}_{11}$ compound at ambient atmosphere. According to charge neutralization, the corresponding weight percentages are derived to be $33.3 \%$ and $66.7 \%$, respectively. This resulted in an average oxidation state of +3.67 . Based on the recorded XANES spectra, the corresponding absorption edge was located at a photon energy of $5968.1 \mathrm{eV}$. Main peaks at $5970.4 \mathrm{eV}$ and $5981.2 \mathrm{eV}$ contributed to $4 f^{2}$ and $4 f^{1}$ electronic configurations, respectively (Ogier et al., 2019). As the temperature reaches $470 \mathrm{~K}$, the absorption edge shifts significantly towards lower energy. This indicates the reduction of Pr ions: $\operatorname{Pr}^{4+}$ ions were partially reduced to $\operatorname{Pr}^{3+}$ ions. As a result, the intense peak of $\mathrm{Pr}^{4+}$ species at $5981.5 \mathrm{eV}$ decreased as a function of temperature. This can be attributed to the increasing ratio of $\mathrm{Pr}^{3+} / \mathrm{Pr}^{4+}$. Furthermore, the white line peak of $\mathrm{Pr}^{4+}$ species at $5981.2 \mathrm{eV}$ was absent when the reduction process was completely finished at $1273 \mathrm{~K}$. This is in good accordance with the work of Luo et al. (2006), which reported that $\operatorname{Pr}_{6} \mathrm{O}_{11}$ was reduced at high temperature and completely transformed to $\mathrm{Pr}_{2} \mathrm{O}_{3}$ around that temperature.

Moreover, we determined the weight percentage of the crystalline phases of $\operatorname{Pr}_{6} \mathrm{O}_{11}$ and $\operatorname{Pr}_{2} \mathrm{O}_{3}$ during reduction under $\mathrm{H}_{2}$ atmosphere by processing a linear combination fit (LCF) for the energy range -30 to $30 \mathrm{eV}$ from the $\operatorname{Pr} L_{3}$ absorption edge. The fit results are demonstrated in Table 3 , and suggest

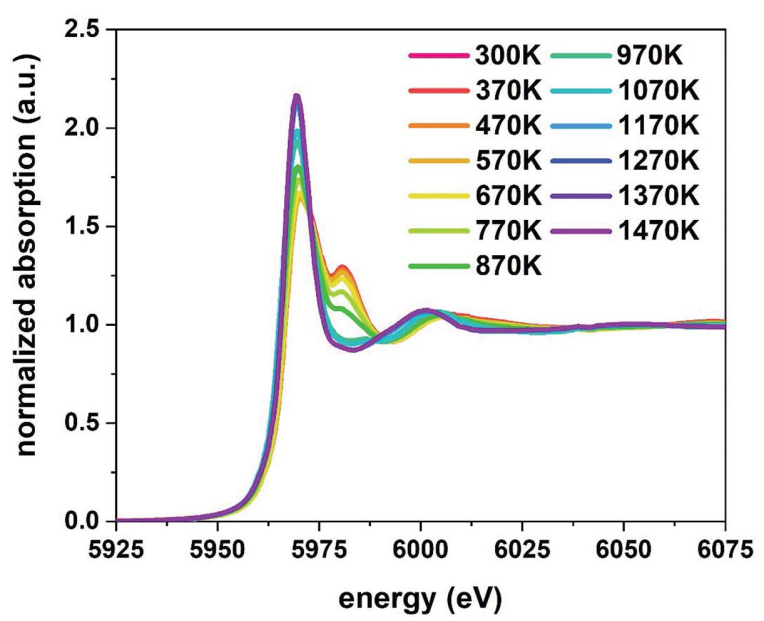

Figure 5

Normalized XANES spectra of $\operatorname{Pr}_{6} \mathrm{O}_{11}$ measured at the $\operatorname{Pr} L_{3}$-edge from $300 \mathrm{~K}$ to $1473 \mathrm{~K}$. 
Table 3

Weight percentages of $\mathrm{Pr}^{3+}$ and $\mathrm{Pr}^{4+}$ cations in the sample at various temperatures.

\begin{tabular}{rccc}
\hline Temperature $(\mathrm{K})$ & $\operatorname{Pr}^{3+}(\mathrm{wt} \%)$ & $\operatorname{Pr}^{4+}(\mathrm{wt} \%)$ & $R$-factor \\
\hline 300 & 33.3 & 66.7 & 0.001 \\
370 & 36.8 & 63.2 & 0.003 \\
470 & 40.6 & 59.4 & 0.005 \\
570 & 45.7 & 54.3 & 0.005 \\
670 & 51.9 & 48.1 & 0.005 \\
770 & 54.5 & 45.5 & 0.006 \\
870 & 69.7 & 30.3 & 0.008 \\
970 & 85.5 & 14.5 & 0.011 \\
1070 & 97.7 & 2.3 & 0.007 \\
1170 & 99.7 & 0.3 & 0.000 \\
1270 & 100.0 & 0 & 0.000 \\
1370 & 100.0 & 0 & 0.000 \\
1470 & 100.0 & 0 & 0.000 \\
\hline
\end{tabular}

that $R$-factors of all fitting results are below 0.015 , indicating high accuracy and reliability of the LCF fitting.

\subsection{Ni K-edge XANES}

$\mathrm{NiO}$ commercial powders were mixed with boron nitride powders in order to dilute the Ni content and compressed into pellets. A pellet was placed in the sample holder at an angle of $45^{\circ}$ and loaded together into the center of the furnace for in situ fluorescence XAS operation. XANES measurements were carried out by probing $\mathrm{Ni}$ at $8333 \mathrm{eV}$. The in situ beamline configuration was set up as previously described in Section 3.1. Here, the SDD detector was utilized for measuring the XAS signal. The water cooling temperature was set at $283 \mathrm{~K}$ to prevent heat damage to the SDD. The heating steps were programmed from room temperature to $773 \mathrm{~K}$ to investigate the reduction process of $\mathrm{Ni}^{2+}$ ions in $\mathrm{NiO}$ compounds under $\mathrm{H}_{2}$ flowing gas with a heating rate of $20 \mathrm{ml} \mathrm{min}^{-1}$. Also, XANES spectra of $\mathrm{Ni}$ foil and $\mathrm{NiO}$ compound with space group $F m \bar{c} m$ were recorded under ambient conditions and used as references for $\mathrm{Ni}^{0}$ and $\mathrm{Ni}^{2+}$ species. The results are shown in Fig. 6.

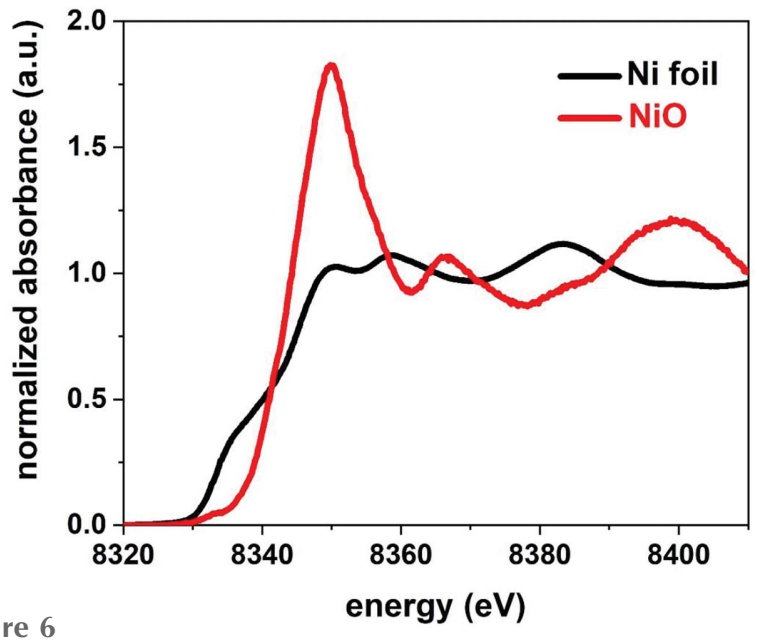

Figure 6

$\mathrm{Ni} K$-edge XANES spectra of $\mathrm{Ni}$ foil and $\mathrm{NiO}$ compound, recorded at room temperature.
Table 4

Weight percentages of $\mathrm{Ni}^{0}$ and $\mathrm{Ni}^{2+}$ species in $\mathrm{NiO}$ sample at various temperatures.

\begin{tabular}{lcll}
\hline Temperature $(\mathrm{K})$ & $\mathrm{Ni}^{0}(\mathrm{wt} \%)$ & $\mathrm{Ni}^{2+}(\mathrm{wt} \%)$ & $R$-factor \\
\hline 370 & 1.7 & 98.3 & 0.0002 \\
420 & 1.6 & 98.4 & 0.0002 \\
470 & 0.9 & 99.1 & 0.0002 \\
520 & 0.6 & 99.4 & 0.0002 \\
570 & 0.5 & 98.5 & 0.0002 \\
620 & 27.9 & 72.1 & 0.0002 \\
670 & 75.6 & 24.4 & 0.0002 \\
720 & 92.1 & 7.9 & 0.0002 \\
770 & 100.0 & 0.0 & 0.0002 \\
\hline
\end{tabular}

Figure 7

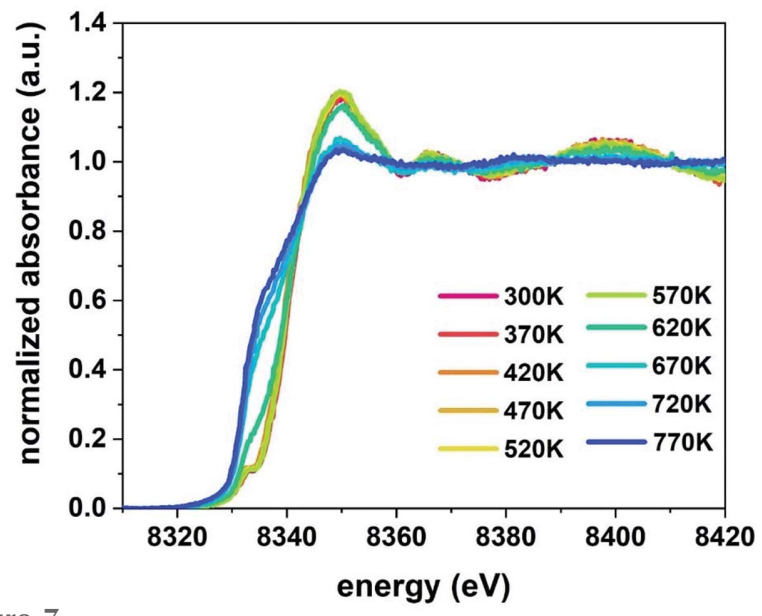

$\mathrm{Ni} K$-edge XANES spectra of $\mathrm{NiO}$ compound recorded at various temperatures.

Fig. 6 shows absorption edges at $8333.3 \mathrm{eV}$ and $8344.4 \mathrm{eV}$ for $\mathrm{Ni}$ foil and $\mathrm{NiO}$, respectively. As a result, these characteristic values can be used as references for $\mathrm{Ni}^{0}$ and $\mathrm{Ni}^{2+}$ species.

Considering the $\mathrm{Ni} K$-edge XANES spectra of $\mathrm{NiO}$ compound recorded at various temperatures (see Fig. 7), its absorption edge obviously decreased from $620 \mathrm{~K}$. It is noteworthy that the intensity of the white line peak at $8351 \mathrm{eV}$, generated by scattering between central $\mathrm{Ni}$ atoms and surrounding $\mathrm{O}$ atoms, also declined. This suggests that $\mathrm{Ni}^{2+}$ ions were partially reduced to $\mathrm{Ni}^{0}$ metallic species with increasing temperature. The spectrum recorded at $770 \mathrm{~K}$ is similar to that of the $\mathrm{Ni}$ foil. As shown in Table 4, the reduction process was completely finished at $770 \mathrm{~K}$.

\section{Conclusions}

The design, fabrication and performance of a compact furnace for in situ heating XAS experiments have been described. The furnace can be easily installed at XAS synchrotron facilities for measurements in transmission and fluorescence modes from 300 to $1473 \mathrm{~K}$ with no heating fluctuation. The maximum heating rate exceeds $20 \mathrm{~K} \mathrm{~min}^{-1}$. The experimental atmosphere can be controlled by flowing or mixing gas with an adjustable flow rate from 1 to $100 \mathrm{ml} \mathrm{min}^{-1}$. The furnace was 
successfully set up at beamline 5.2 (SLRI, Thailand) for in situ XAS operation. Transmission XANES spectra at various temperatures indicated the reduction of $\operatorname{Pr}$ ions in $\operatorname{Pr}_{6} \mathrm{O}_{11}$ catalyst compounds under $\mathrm{H}_{2}$ reducing atmosphere (average oxidation state from +3.67 to +3 ) and the phase transition $\mathrm{Pr}_{6} \mathrm{O}_{11} \rightarrow \mathrm{Pr}_{2} \mathrm{O}_{3}$ at $1173 \mathrm{~K}$. Further, in situ XAS spectra of $\mathrm{Ni}$ in fluorescence mode showed the reduction of $\mathrm{Ni}^{2+}$ ions to $\mathrm{Ni}^{0}$ metallic species at $620 \mathrm{~K}$. Therefore, our furnace is very suitable for investigation of temperature-dependent structure transitions such as metallic melts, nanoparticles phase-change and the solidification process of crystalline materials.

\section{Funding information}

Funding and the well equipped machine shop were supported by the Synchrotron Light Research Institute (SLRI) in Thailand. This work has been partially supported by the Research Network NANOTEC (RNN) program of the National Nanotechnology Center (NANOTEC), National Science and Technology Development Agency (NSTDA), Ministry of Higher Education, Science, Research and Innovation (MHESI), Thailand.

\section{References}

An, P., Hong, C., Zhang, J., Xu, W. \& Hu, T. (2014). J. Synchrotron Rad. 21, 165-169.

Bokhoven, J. A. van, van der Eerden, A. M. J., Smith, A. D. \& Koningsberger, D. C. (1999). J. Synchrotron Rad. 6, 201-203.

Bolin, T. B., Wu, T., Schweitzer, N., Lobo-Lapidus, R., Kropf, A. J., Wang, H., Hu, Y., Miller, J. T. \& Heald, S. M. (2013). Catal. Today, 205, 141-147.

Boonruang, C., Thong-on, A. \& Kidkhunthod, P. (2018). Sci Rep, 8 , 2289.

Chin, Y. Y., Lin, H., Hu, Z., Shimakawa, Y. \& Chen, C. (2019). Physica B, 568, 92-95.

Deb, A., Ralph, J. M., Cairns, E. J. \& Bergmann, U. (2006). Phys. Rev. $B, \mathbf{7 3}, 115114$.

Eerden, A. M. J. van der, van Bokhoven, J. A., Smith, A. D. \& Koningsberger, D. C. (2000). Rev. Sci. Instrum. 71, 3260-3266.

Grunwaldt, J.-D., Kappen, P., Hammershøi, B. S., Tröger, L. \& Clausen, B. S. (2001). J. Synchrotron Rad. 8, 572-574.

Hashimoto, T., Yoshiasa, A., Okube, M., Okudera, H. \& Nakatsuka, A. (2007). AIP Conf. Proc. 882, 428-430.
Huwe, H. \& Fröba, M. (2004). J. Synchrotron Rad. 11, 363-365.

Inukai, K., Iwai, H., Takahashi, Y. \& Shin, W. (2015). Ceram. Int. 41, 2852-2862.

Jaiban, P., Watcharapasorn, A., Yimnirun, R., Guo, R. \& Bhalla, A. S. (2018). J. Alloys Compd. 759, 120-127.

Kappen, P., Grunwaldt, J., Hammershøi, B. S., Tröger, L. \& Clausen, B. S. (2001). J. Catal. 198, 56-65.

Lamberti, C., Prestipino, C., Bordiga, S., Berlier, G., Spoto, G., Zecchina, A., Laloni, A., La Manna, F., D'Anca, F., Felici, R., D'Acapito, F. \& Roy, P. (2003). Nucl. Instrum. Methods Phys. Res. B, 200, 196-201.

Luo, M.., Yan, Z.. \& Jin, L.. (2006). J. Mol. Catal. A, 260, 157162.

Marini, C., Diaz-Rovira, A. M., Kennedy, B. J. \& Joseph, B. (2018). J. Mater. Eng. Perform. 27, 6322-6327.

Massa, N. E., Ramos, A. Y., Tolentino, H. C. N., Sousa-Neto, N. M., Fonseca, J. Jr \& Alonso, J. A. (2015). Mater. Res. Expr. 2, 126301.

Mastelaro, V. \& Zanotto, E. (2018). Materials (Basel), 11, 204.

Mathisen, K., Kirste, K. G., Hargreaves, J. S. J., Laassiri, S., McAulay, K., McFarlane, A. R. \& Spencer, N. A. (2018). Top. Catal. 61, 225239.

Meneses, C. T., Flores, W. H., Sotero, A. P., Tamura, E., Garcia, F. \& Sasaki, J. M. (2006). J. Synchrotron Rad. 13, 468-470.

Ogier, T., Prestipino, C., Figueroa, S., Mauvy, F., Mougin, J., Grenier, J. C., Demourgues, A. \& Bassat, J. M. (2019). Chem. Phys. Lett. 727, 116-120.

Ravel, B. \& Newville, M. (2005). J. Synchrotron Rad. 12, 537-541.

Song, T., Yao, W., Kiadkhunthod, P., Zheng, Y., Wu, N., Zhou, X., Tunmee, S., Sattayaporn, S. \& Tang, Y. (2020). Angew. Chem. Int. Ed. 59, 740-745.

Sriplai, N., Koowattanasuchat, S., Kidkhunthod, P., Chanlek, N., Eichhorn, S. J. \& Pinitsoontorn, S. (2018). J. Alloys Compd. 739, 19-29.

Steiner, C., Gänzler, A. M., Zehentbauer, M., Hagen, G., Casapu, M., Müller, S., Grunwaldt, J. \& Moos, R. (2019). Top. Catal. 62, $227-$ 236.

Sumrunronnasak, S., Chanlek, N. \& Pimpha, N. (2018). Mater. Chem. Phys. 216, 143-152.

Tamura, K., Inui, M. \& Hosokawa, S. (1995). Rev. Sci. Instrum. 66, 1382-1384.

Yamamoto, Y., Suzuki, A., Tsutsumi, N., Katagiri, M., Yamashita, S., Niwa, Y., Katayama, M. \& Inada, Y. (2018). J. Solid State Chem. 258, 264-270.

Yao, W., Armstrong, A. R., Zhou, X., Sougrati, M. T., Kidkhunthod, P., Tunmee, S., Sun, C., Sattayaporn, S., Lightfoot, P., Ji, B., Jiang, C., Wu, N., Tang, Y. \& Cheng, H. M. (2019). Nat. Commun. 10, 3483.

Zhao, N., Yao, M. J., Ma, H. T. \& Wong, C. P. (2017). J. Mater. Sci. Mater. Electron. 28, 8824-8831. 